\title{
Performance comparison of hybrid active power filter for P-Q theory and SVPWM technique
}

\author{
T. M. Thamizh Thentral, K. Vijayakumar, R. Jegatheesan \\ Department of Electrical and Electronics Engineering, SRM Institute of Science and Technology, India
}

\begin{tabular}{l} 
Article Info \\
\hline Article history: \\
Received Oct 30, 2019 \\
Revised Jun 14, 2020 \\
Accepted Jul 4, 2020 \\
\hline
\end{tabular}

\section{Keywords:}

Harmonic distortion Hybrid active power filter SRF theory P-Q theory

SVPWM

\begin{abstract}
Harmonic Distortion in many of the industrial applications are occur primarily owing to the enormous utilization of loads with high non-linearity like power converters, speed varying drives and arc furnaces. The power semiconductor is used to achieve the variation in speed and conversion from one source to another. Mostly active filters and tuned filters are utilized to remove the harmonic included in the source current. The tuned passive filters and inductance inserted in the line reduces the harmonics but at the same time induces the resonances in most of the industrial applications. Due to this, harmonic distortion increases in the source current and voltage. This can be reduced by adding hybrid filter in the system with decreased rating of active filter in high power applications. This article deals with the various topology of hybrid filters. The working of the proposed filter design in variable inductance mode based on the pollution created in the source voltage and current is studied. In the proposed hybrid filter passive filter is tuned with seventh harmonic frequency and connected in series with active filters to reduce the harmonic distortion. DC link voltage and the active filter VA rating could be minimized. The control signal to the filter is derived from P$\mathrm{Q}$ theory and space vector pulse width modulation (SVPWM). The performance of the system under study is simulated and noted for the THD percentage before and after the filter is added to the system and the same model is experimented with reduced voltage level.
\end{abstract}

This is an open access article under the CC BY-SA license.

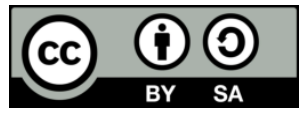

\section{Corresponding Author:}

T. M. Thamizh Thentral,

Department of Electrical and Electronics Engineering,

SRM Institute of Science and Technology,

SRM Nagar, Kattankulathur-603023, Chengalpettu District, Chennai, India.

Email: thentral2kuna@gmail.com

\section{INTRODUCTION}

The reason for intensifications of deviation in the voltage and current in supply side is mainly because of the loads which produce non-linearity in the power systems. The non-linear loads such as variable speed drive systems, switched mode power supply, uninterrupted power supply and battery charging systems are fitted with the semiconductor devices as their switching components, due to less cost and easy control to achieve power conversion. The power converters present in the power system will increase the harmonic current leads to huge harmonic distortion. The sensitive equipment may be subjected to malfunctioning because of such harmonic distortion. Generally, tuned passive filters are employed at the other end of the distribution transformer to suppress the harmonic content present along with the fundamental current by providing low impedance path $[1,2]$. Since, passive filters can be used only for fixed compensation, there may be a chance of series or parallel resonance among the line inductance and passive filter. This will worsen 
the function of a passive filter, due to which additional harmonic may arise $[3,4]$. To overcome this resonance problem various active filters are employed.

The active filters are classified based on their contribution with the load and source side as shunt and series to provide current and voltage compensation respectively [5-7]. However, when load requirement of the system increases leads to higher rating of filter also may not get the effective elimination of harmonic resonance [8]. So, a combination of active with passive filters promises a better solution for the reduction of harmonic resonance and current $[9,10]$. Further the active and passive filter can be connected in either series or parallel way. A non-linear load of 10KVA rating that is a six-pulse uncontrolled bridge rectifier is taken as a case study. A displacement factor of 0.95 is considered for analysis. A comparison is made between the hybrid active power filter (HAPF) and shunt active power filter (SAPF) on the basis of system performance [11]. Synchronous reference frame (SRF) control strategy is used to extract the compensating current in this method. The line current distortion, DC voltage value, inverter voltage and current, overall inverter size and overall inverter voltage is discussed. Earlier, for a three-phase controlled bridge rectifier of $20 \mathrm{kVA}$ rating, series active filter is connected in series with the shunt passive filter. Further that is inserted into the line in series through 10:1 transformer [12]. This combination reduces the active filter rating. The series active filter act as a harmonic isolator and shunt passive filter reduces the harmonic current. A SAPF with ripple filter and passive filter with transformer is considered to design the hybrid filter for reactive power compensation, harmonic elimination and voltage unbalance compensation [13-15]. Recently, HAPFs without transformers were proposed for compensating harmonic current in the industrial power system applications [16-22].

A transformer-less HAPF is constructed by shunt active filter connected in series with a seventhtuned passive filter to further reduce the VA rating of the active filter. It functions as an adjustable conductance in harmonic resonant frequencies based on the THD. Hence a satisfactory level of distortion in harmonics can be offered for a varying load condition. The fundamental component of a supply voltage can be sustained better by the proper designing of series capacitor. A less DC link voltage is enough to operate an active filter [16, 21], while comparing with SAPF. A three-phase star connected system with loads of linearity and non-linearity in operation is linked at PCC (point of common coupling) is considered to design the transformer-less hybrid active filter. The instantaneous reactive power theory and SVPWM methods are used to generate the compensating control signal. The performance of the filter is analyzed by comparing the system with both the PWM methods.

The general introduction and the concept of hybrid active filter unit (HAPU) used is discussed in section 1. The general introduction of the active power filter is explained in section 2. The HAPF topology and its operating principle and also the control techniques for the HAPF are discussed in section 3. The simulink model of a HAPF with its output waveforms and hardware picture with the output graphs are shown in section 4 and section 5. The conclusion drawn from the work is given in section 6 .

\section{ACTIVE POWER FILTER}

The APFs (active power filter) are classified into series, shunt and hybrid APF. In series APF, the inverter acting as a filter is linked in series with line for providing voltage compensation. On the other hand, the PWM based VSI (voltage source inverter) acting as a filter is coupled parallel to the source and load to inject negative harmonic current to the line, hence the harmonic current can be to eliminate harmonic current present in the load side. In the same manner, the hybrid filter can have the combination of active and passive filters connected in series or parallel and the combination of shunt and series active filters based on the load applications.

The general block diagram of APF is shown in Figure 1. The diagram mainly considers supply, load source impedance and filter. Considering the supply, it can be used as single phase, three phase three wire and three phase four wire AC supply. It is the first stage of this project. So it gives the AC supply to the rectifier. The input side has one inductive filter. It is used to improve the input power factor. The load at the point of common coupling can be linear load, non-linear load or the combination of both. The voltage source inverter is connected as a filter to provide the voltage and current compensation.

Active and passive power filters are considered as the traditional filters for harmonic elimination Passive power filter is simple and easy to design but has the drawback of resonance tuning problem. Active filter is introduced to overcome the additional resonance but initial and running cost is high as the power rating increases. HAPF overcome these disadvantages by acting as a harmonic isolator, at fundamental frequency zero impedance to the external circuit and high resistance to source or load harmonics. There are different topologies in hybrid power filter based on the connection between the passive and active filter. The three basic topologies of HAPF are discussed in this paper. 


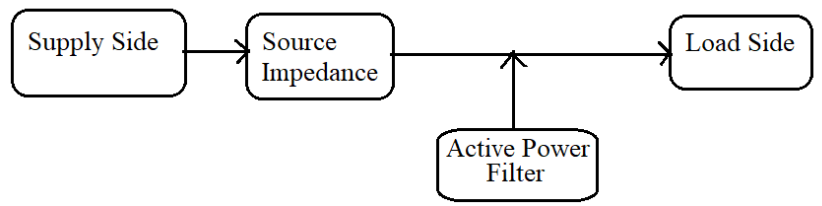

Figure 1. General block diagram of APF

\section{PROPOSED HYBRID ACTIVE POWER FILTER TOPOLOGY}

The proposed topology of the transformer-less HAPF is given in Figure 2. In this simplified circuit diagram, where $L_{s}$ and $R_{s}$ are the source impedance. The HAPF is designed with shunt active filter connected in series with passive filter is which arranged in parallel to the load [22-24]. The passive filter $L_{f}$ and $C_{f}$ is tuned to seventh order harmonic frequency. The seventh tuned passive filter eliminates the harmonic current and provides power compensation. The performance of the passive filter is improved through voltage source inverter with DC link capacitor. Suppression in harmonic resonance is achieved by operating the filter in variable conductance mode. The load at the point of coupling is both linear and non-linear load. A three-phase uncontrolled bridge rectifier with resistive load is the non-linear load in this proposed method.

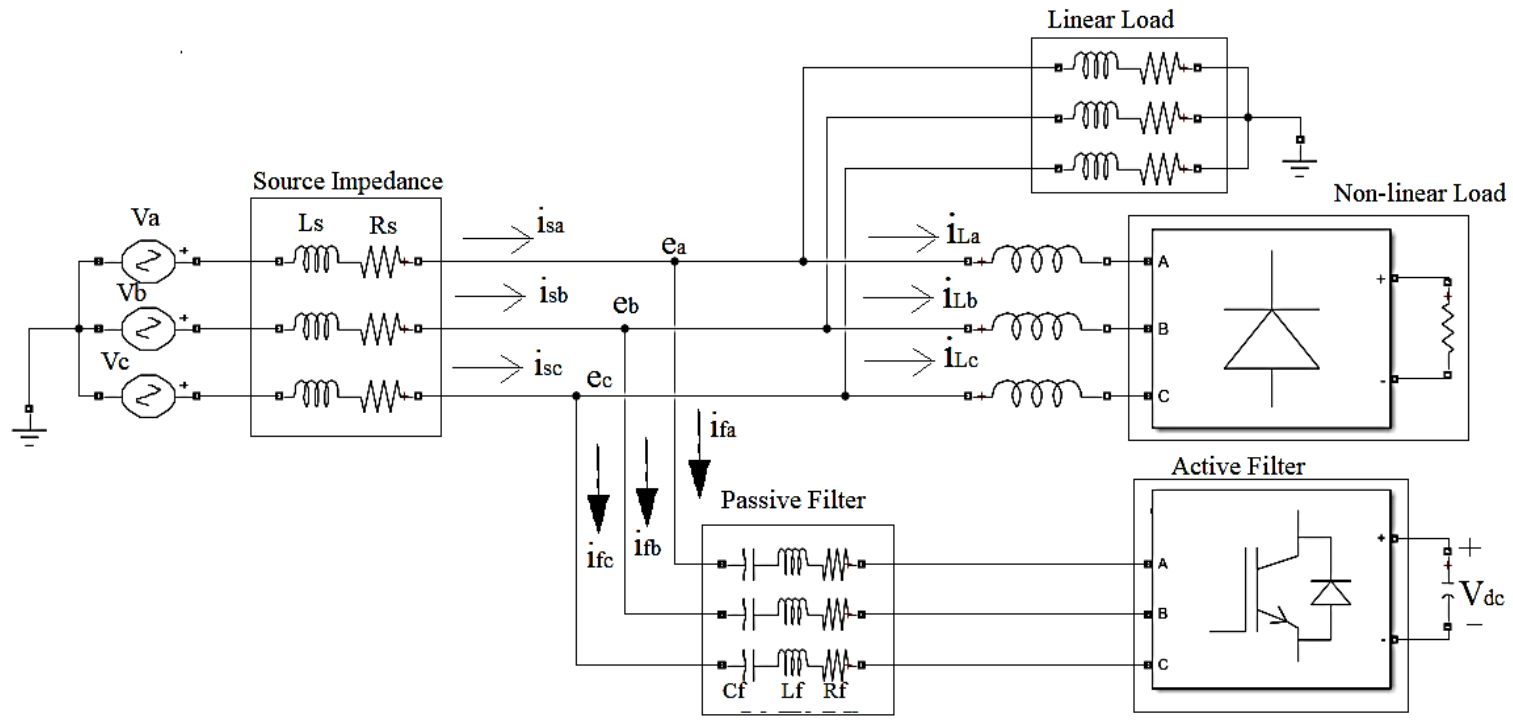

Figure 2. Block diagram of HAPF

The performance filter is analysed with total harmonic distortion obtained in both the system. As per the IEEE std. 519-1992 recommended practices [25], the voltage and current THD\% must be maintained less than 5\%, and individual distortion should be below 4\%. Designing the filter in conventional method is complex for different harmonics. It also requires individual control loops for compensating the voltage and current. In the proposed system, the voltage level is maintained during fault conditions. It provides sufficient grid side voltage recovery and better voltage compensation. This proposed system can be used to improve power quality, voltage stability and power control in grid.

\subsection{Space vector pulse width modulation}

The control signal to the inverter module is controlled from various pulse width modulation techniques. In this paper a space vector pulse width modulation technique is used to generate the control signal to the inverter. The results obtained from the SVPWM [24, 26] method is compared with the results derived from the Instantaneous reactive power theory.

The reference vector is sampled at the fixed clock frequency $2 f_{s}$ to obtain the SVM for three-leg inverter. There are eight possible switching combinations in the three-leg inverter. These switching combinations are mapped with the orthogonal plane to get the six non-zero vectors and two zero vectors. 
The six non-zero switching vectors from 1-6 form a hexagon which is projected in Figure 3. The upper three switches and the lower three switches in the three-leg inverter can have the eight possible switching combinations of ON and OFF patterns. Both the upper and lower switches are complementing each other.

To perform the SVM modulation there exists four steps. In the first step the reference vector to be obtained by mapping the three phase signals to the orthogonal d-q co-ordinates. To synthesize the reference vector for one switching cycle switching vectors has to be selected including zero and non-zero vectors in the second step. By using simple trigonometric algorithm, the time duration for all selected switching vector is to be calculated in the third step. In the fourth step switching vectors are sequenced and given into the switching network. The modulation algorithm is given as a flowchart in the Figure 4.

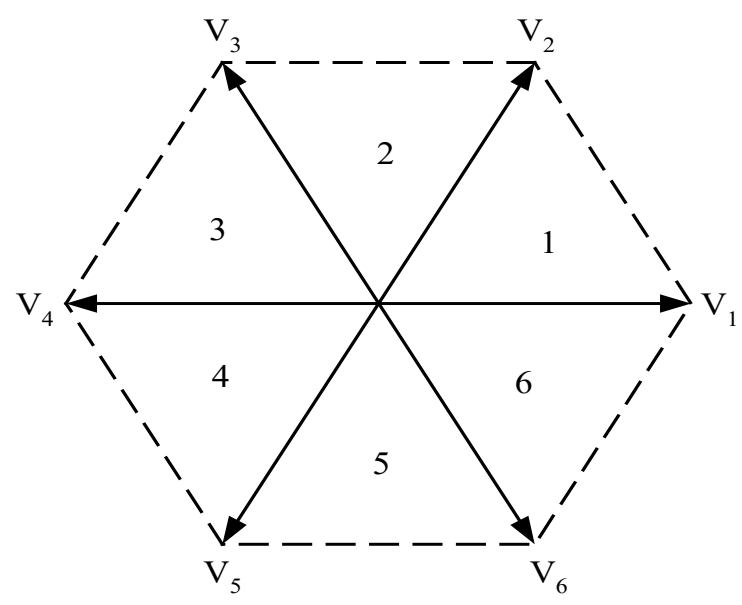

Figure 3. Vector representation

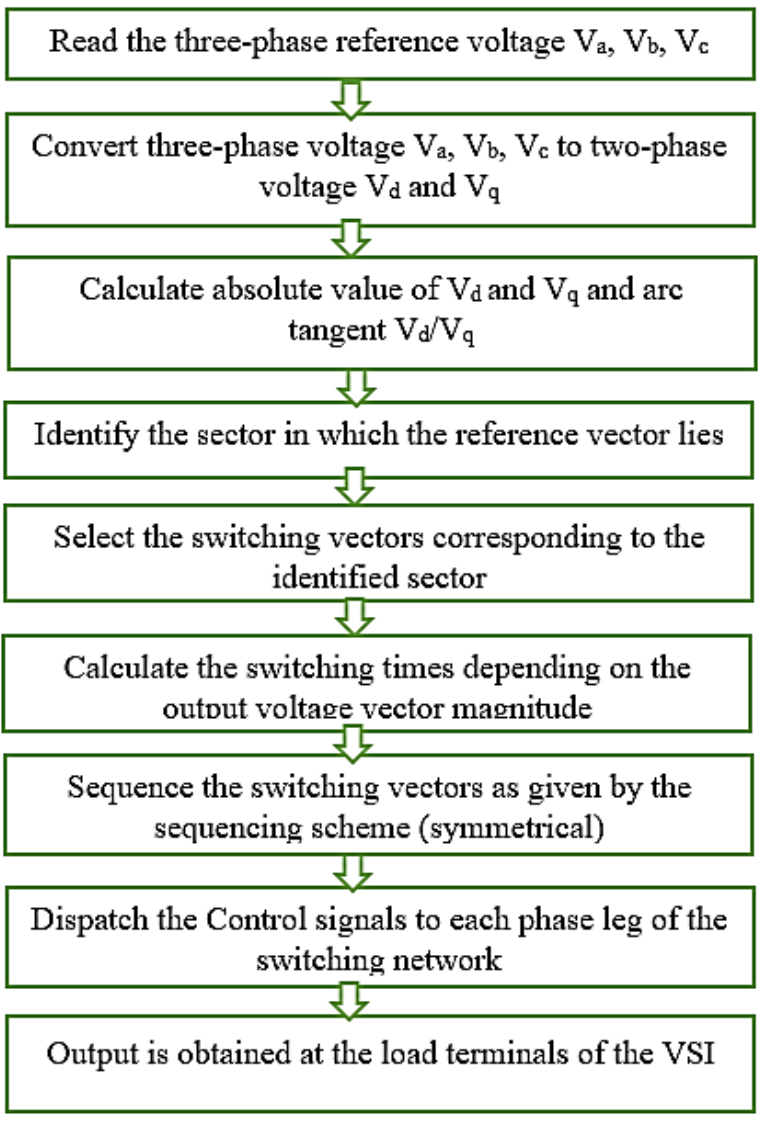

Figure 4. Modulation algorithm for SVPWM 


\subsection{Filter design using $\mathrm{P}-\mathrm{Q}$ theory}

In this section a filter designed by using $\mathrm{P}-\mathrm{Q}$ theory to reduce the harmonics. The three-phase voltage and current at the point of common coupling is transferred from three-phase coordinates to $\alpha-\beta-0$ coordinates which is given in (1) and (2). From (3) and (4) the real and reactive power is calculated. Then again it is converted in to three-phase phase coordinates as in equation (5) to inject the negative harmonic current to reduce the THD percentage [27-29].

$$
\begin{aligned}
& {\left[\begin{array}{l}
v_{0} \\
v_{\alpha} \\
v_{\beta}
\end{array}\right]=\sqrt{\frac{2}{3}} \cdot\left[\begin{array}{cccc}
\frac{1}{\sqrt{2}} \frac{1}{\sqrt{2}} & \frac{1}{\sqrt{2}} & \\
1 & \frac{-1}{2} & \frac{-1}{2} \\
0 & \frac{\sqrt{3}}{2} & \frac{-\sqrt{3}}{2}
\end{array}\right] \cdot\left[\begin{array}{l}
v_{a} \\
v_{b} \\
v_{c}
\end{array}\right]} \\
& {\left[\begin{array}{l}
i_{0} \\
i_{\alpha} \\
i_{\beta}
\end{array}\right]=\sqrt{\frac{2}{3}} \cdot\left[\begin{array}{ccc}
\frac{1}{\sqrt{2}} \frac{1}{\sqrt{2}} \frac{1}{\sqrt{2}} & \\
1 & \frac{-1}{2} & \frac{-1}{2} \\
0 & \frac{\sqrt{3}}{2} & \frac{-\sqrt{3}}{2}
\end{array}\right] \cdot\left[\begin{array}{l}
i_{a} \\
i_{b} \\
i_{c}
\end{array}\right]} \\
& {\left[\begin{array}{l}
p \\
q
\end{array}\right]=\left[\begin{array}{cc}
\mathrm{v}_{\alpha} & \mathrm{v}_{\beta} \\
-v_{\beta} & \mathrm{v}_{\alpha}
\end{array}\right] \cdot\left[\begin{array}{l}
i_{\alpha} \\
i_{\beta}
\end{array}\right]}
\end{aligned}
$$

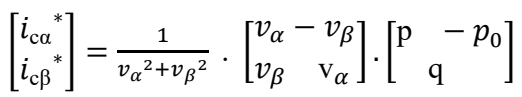

$$
\begin{aligned}
& {\left[\begin{array}{l}
i_{c a} * \\
i_{c b} * \\
i_{c c} *
\end{array}\right]=\sqrt{\frac{2}{3}} \cdot\left[\begin{array}{ccc}
\frac{1}{\sqrt{2}} & 1 & 0 \\
\frac{1}{\sqrt{2}} & \frac{-1}{2} & \frac{\sqrt{3}}{2} \\
\frac{1}{\sqrt{2}} & \frac{-1}{2} & \frac{-\sqrt{3}}{2}
\end{array}\right] \cdot\left[\begin{array}{l}
i_{c 0} * \\
i_{c \alpha} * \\
i_{c \beta} *
\end{array}\right]}
\end{aligned}
$$

\section{SIMULATION REULTS}

In this paper a HAPF is designed for three-phase bridge rectifier supplied from three-phase AC supply, to eliminate the harmonic generated by the no-linear load. HAPF is designed with the combination of SAPF in series with the passive filter to eliminate the harmonics present in the source current. It also reduces the rating of active filter. The system is simulated in Matlab Simulink software and the load and source voltage are observed, and the total harmonic distortion is taken through FFT analysis. After the design of filter in matlab Simulink model, the system is executed for 0.5 seconds. The various waveforms for voltage and current in both the input and output sides of the system without considering the hybrid filter is shown in Figures 5(a) to (f).

The supply voltage waveform is given in Figure 5(a). It shows that the shape of the waveform is almost sinusoidal and the THD percentage is within the recommended value. The load voltage and load current waveform is depicted in Figures 5(b) and (c). It is more distorted due to non-linear load connected to the system and the total harmonic distortion also is not within specified value. The THD \% is noted through FFT analysis and the same is projected in Figures 5(e) and (f). The THD \% without considering the hybrid filter for current is $8.38 \%$ and voltage is measured as $8.32 \%$. The real and reactive power also noted and mentioned in Figure 5(d).

The hybrid filter with seventh tuned passive filter is connected in series to the system and the it is executed for 0.5 seconds again. The control signal to the active poer filter is extracted by using instantaneous reactive power theory with hysteresis current controller and space vector pulse width modulation. The results obtained from both the control method is observed and the same is shown in Figures 6(a)-(d). Figure 6(a) and Figure 6(b) is the source current waveform for P-Q theory ased filter and space vector modulated filter. It shows that in both the cases the current obtained is pure sinusoidal wave shape, by eliminating the harmonic current present in the fundamental current. Figures 6(c) and (d) depict the source voltage for the two PWM methods.

The FFT analysis for load voltage and source current is taken to observe the total harmonic distortion after the filter is connected to the system. The THD percentage for source current in P-Q theory and SVPWM method is reduced to $2.76 \%$ and $2.64 \%$ which is shown in Figures $7(a)$ and (b). The same way the source current and load voltage THD is noticed as 3.35\% and 3.15\% in both the methods. The THD \% for before and after the filter is tabulated in Table 1. 


\section{HARDWARE RESULTS DISCUSSION}

The hardware results have been obtained by feeding the inverter output to the linear and non-linear load. The following graphs are obtained using a digital storage oscilloscope. The hardware model for the HAPF is shown in Figure 8. The control signal for the inverter is obtained by using the PIC Microcontroller "PIC $16 \mathrm{~F} 84 \mathrm{~A}$ ". The output voltage waveform before and after the filter with linear and non-linear load is shown in Figures 9(a) to (d). Figure 9(a) is the output voltage waveform of non-linear load by considering the HAPF. Figure 9(c) depicts the output voltage waveform of non-linear load without HAPF. The output voltage waveform for the system with linear load is shown in Figure 9(b). The output voltage obtained from the hardware model is observed in multimeter, which is shown in Figure 9(d).

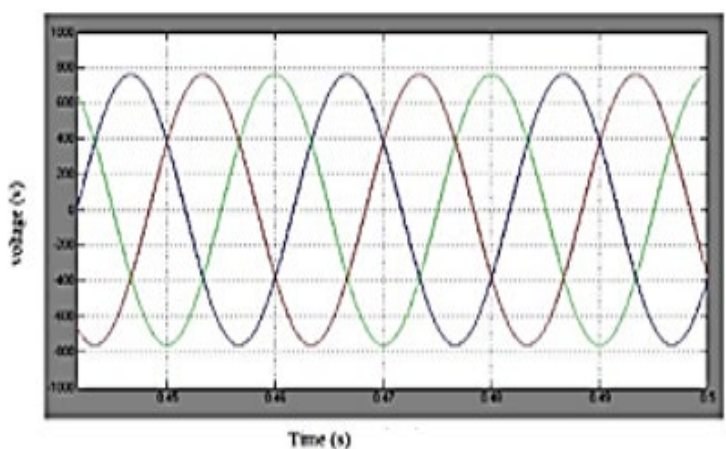

(a)

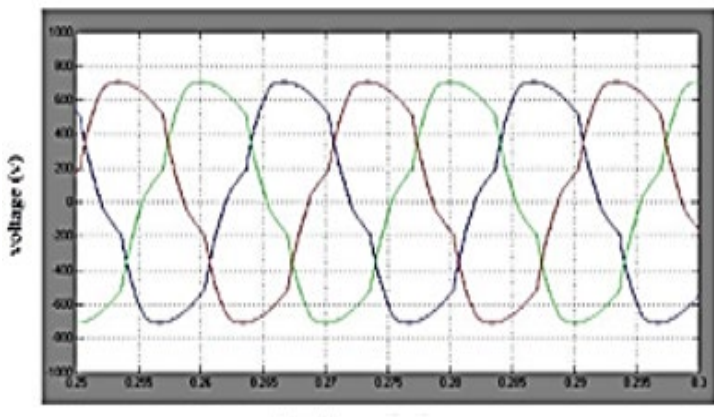

Teme (s)

(c)

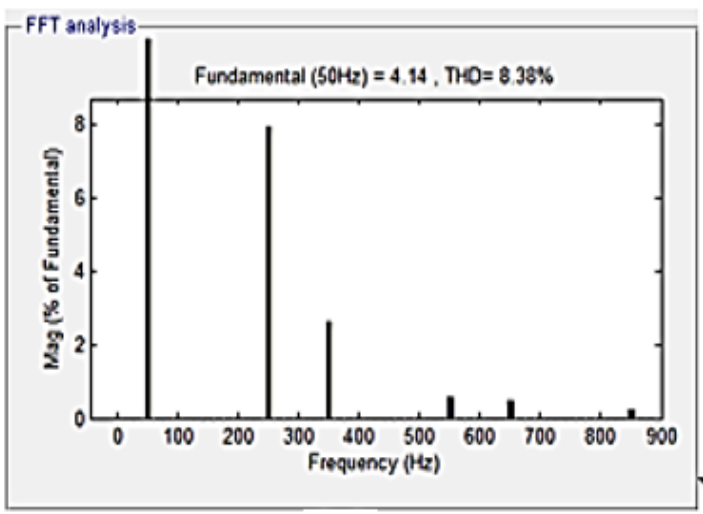

(e)

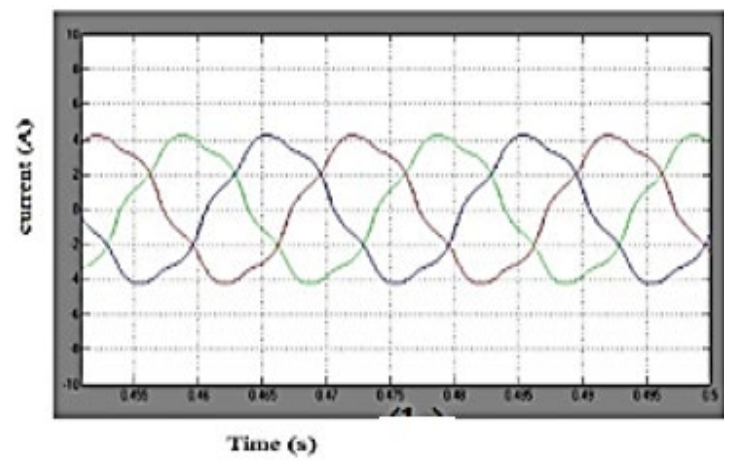

(b)

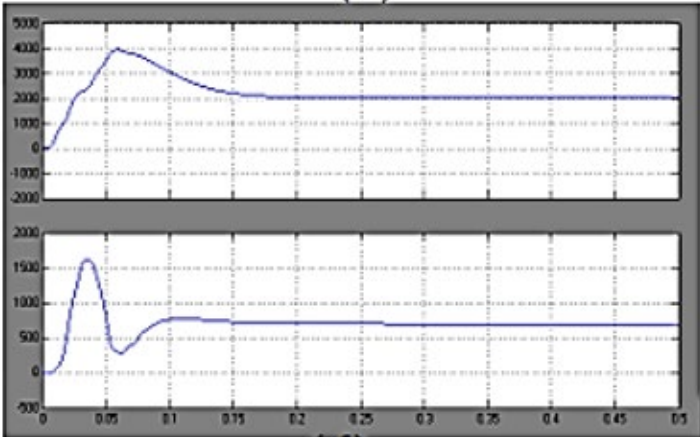

(d)

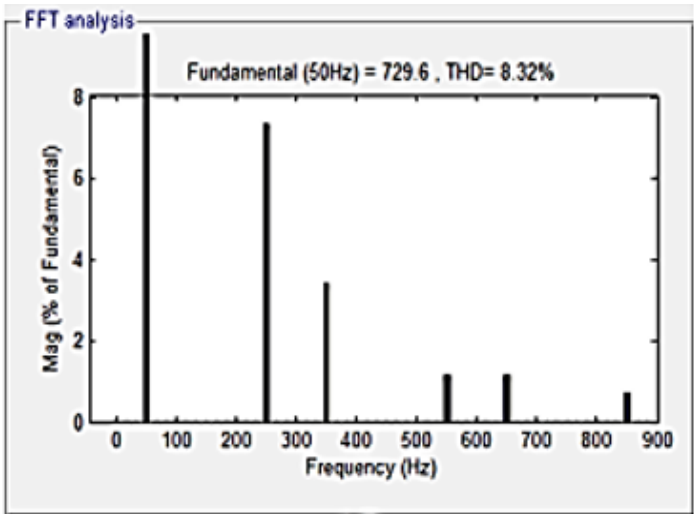

(f)

Figures 5. Voltage and current waveform without hapf: a) source voltage, b) load current, c) load voltage, d) real and reactive power, e) FFT for load voltage and f) FFT for load current 


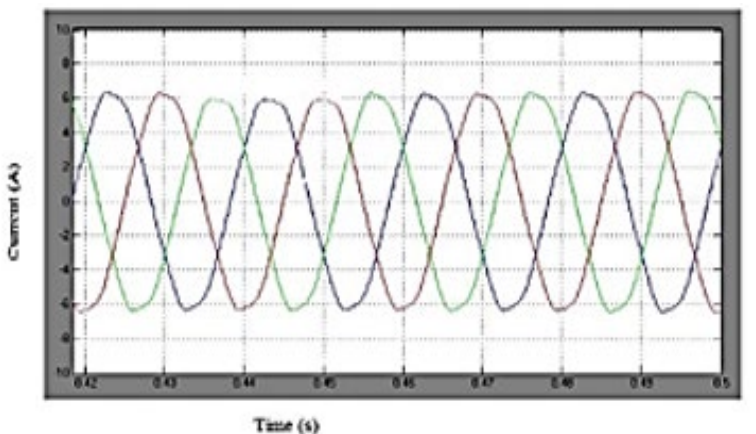

(a)

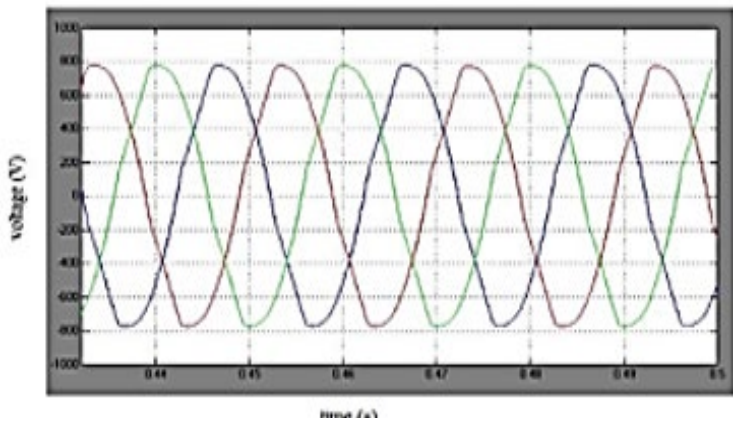

(c)

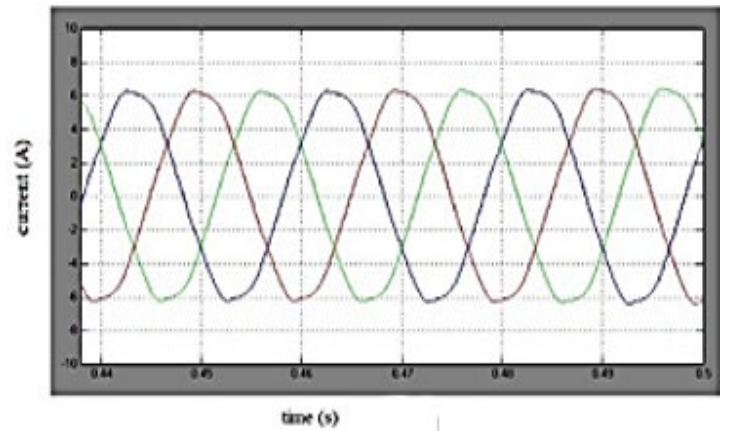

(b)

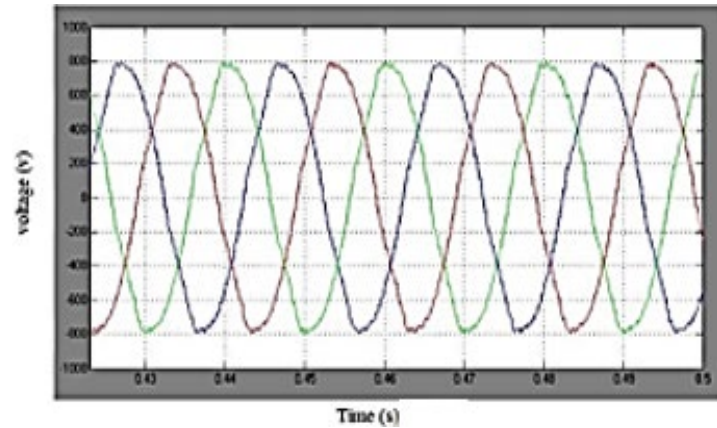

(d)

Figures 6. Voltage and current waveform without HAPF: a) source current with P-Q theory, b) source current with SVPWM c) load voltage with P-Q theory d) load voltage with SVPWM

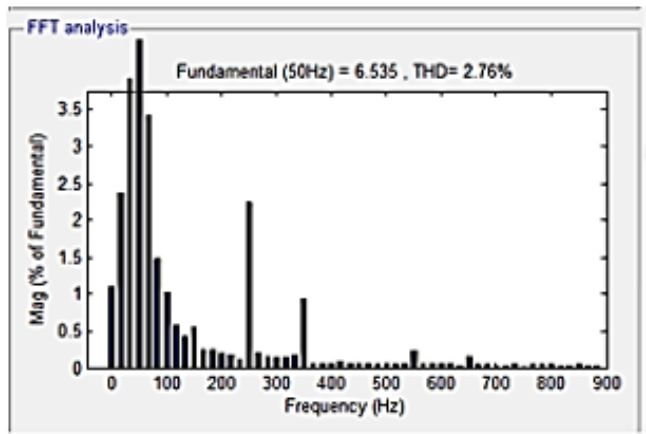

(a)

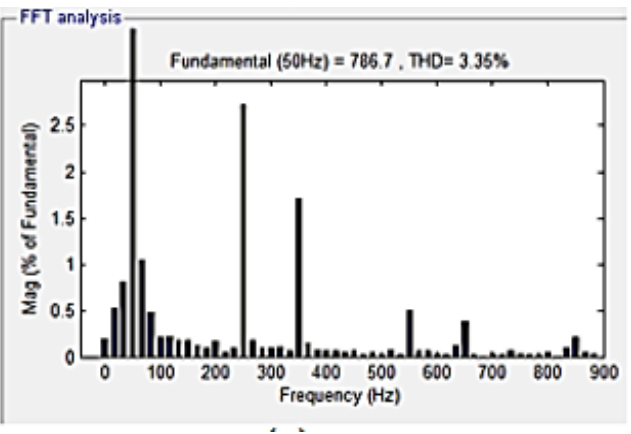

(c)

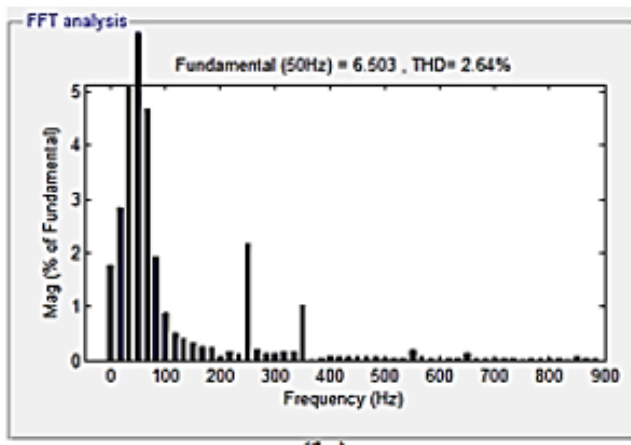

(b)

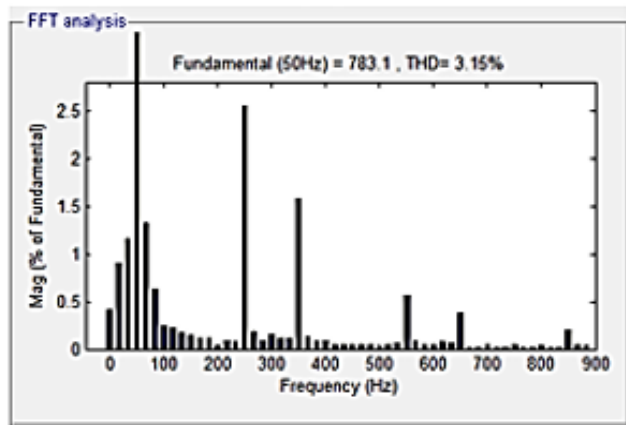

(d)

Figures 7. THD \% of voltage and current waveform with HAPF, a) source current with P-Q theory b) source current with SVPWM, c) load voltage with P-Q theory, d) load voltage with SVPWM 
Table 1. Comparison of THD\% with and without filter

\begin{tabular}{llll}
\hline PARAMETERS & WITHOUT HAPF & WITH HAPF (P-Q theory) & WITH HAPF (SVPWM) \\
\hline Source voltage & $440 \mathrm{~V}$ & 440V & $440 \mathrm{~V}$ \\
Reactive power & $695 \mathrm{VAr}$ & $2200 \mathrm{VAr}$ & $2200 \mathrm{VAr}$ \\
Thd for current & $8.38 \%$ & $2.76 \%$ & $2.64 \%$ \\
Thd for voltage & $8.32 \%$ & $3.35 \%$ & $3.15 \%$ \\
\hline
\end{tabular}

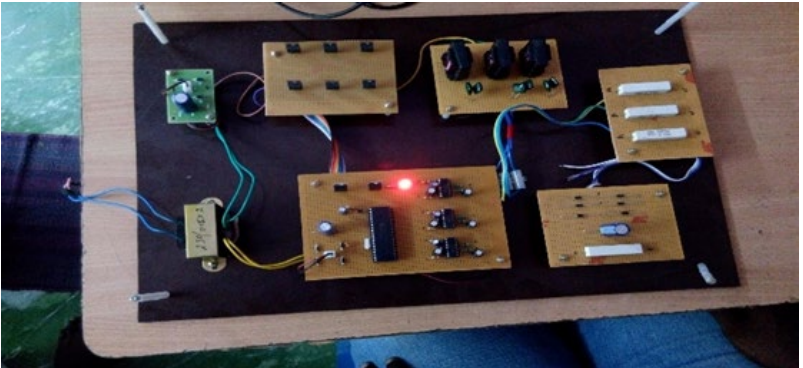

Figure 8. Hardware set up for HAPF

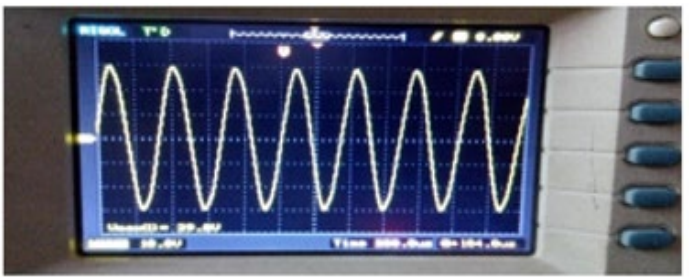

(a)

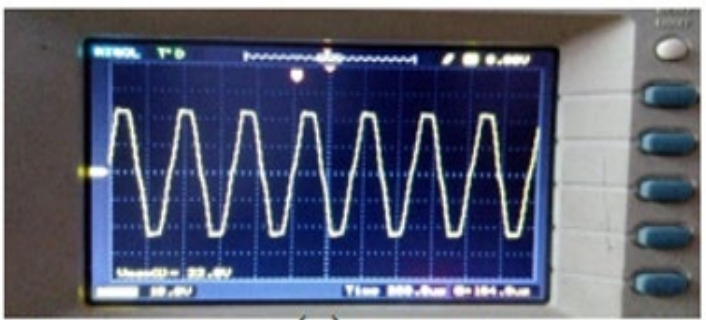

(c)

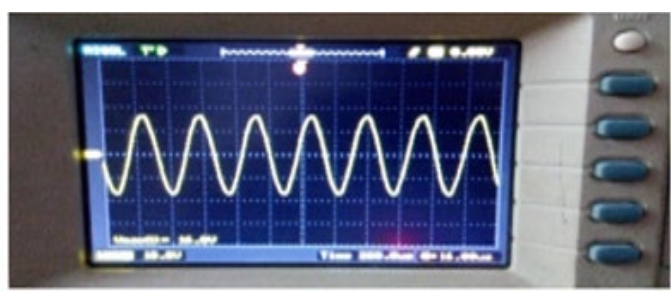

(b)

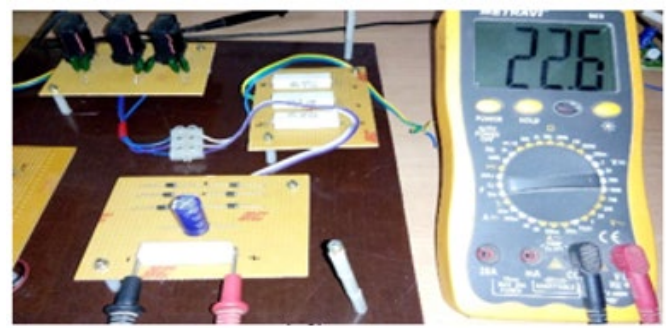

(d)

Figures 9. Output voltage waveform: a) output voltage waveform of non-linear load with HAPF, b) output voltage waveform of non-linear load without HAPF, c) output voltage waveform of linear load, d) output voltage with HAPF

\section{CONCLUSION}

In this paper to eliminate the harmonic resonance a hybrid active filter has been used in industrial power systems. A HAPF is designed to improve the filtering performance of the passive filter and reduce the VA rating of the active filter. In this proposed filter to operate the active filter in variable harmonic conductance mode a seventh harmonic tuned passive filter is connected in series with the active filter. Accordingly, the distortion in the current and voltage is in the recommended value during changes in the load and line impedances. The simulation results for HAPF is designed with P-Q theory and SVPWM techniques to generate the switching pulse to the active filter. The results obtained from both the model is compared. The prototype model of a Hybrid Active Filter Unit fed to a linear load and Non-linear load has been implemented and results were obtained. The pulses generated in the micro controller are amplified in the driver circuit to trigger the inverter switches. The prototype is found to provide satisfactory operation using SVPWM method and it is effective in improving the THD for current and voltage from $8.38 \%$ to $2.64 \%$ and $8.32 \%$ to $3.15 \%$. 


\section{REFERENCES}

[1] R. H. Simpson, "Misapplication of power capacitors in distribution systems with nonlinear loads-three case histories," Conference Record of 2004 Annual Pulp and Paper Industry Technical Conference (IEEE Cat. No.04CH37523), Victoria, BC, Canada, pp. 156-166, 2004.

[2] T. Dionise and V. Lorch, "Voltage distortion on an electrical distribution system," IEEE Industry Applications Magazine, vol. 16, no. 2, pp. 48-55, 2010.

[3] E. J. Currence, J. E. Plizga, and H. N. Nelson, "Harmonic resonance at a medium-sized industrial plant," IEEE Transactions on Industry Applications, vol. 31, no. 4, pp. 682-690, 1995.

[4] C.-J. Wu et al., "Investigation and mitigation of harmonic amplification problems caused by single-tuned filters," IEEE Transactions on Power Delivery, vol. 13, no. 3, pp. 800-806, 1998.

[5] B. Singh, K. Al-Haddad, and A. Chandra, "A review of active filters for power quality improvement," IEEE Transactions on Industrial Electronics, vol. 46, no. 5, pp. 960-971, 1999.

[6] H. Akagi, "Active harmonic filters," in Proceedings of the IEEE, vol. 93, no. 12, pp. 2128-2141, 2005.

[7] Bhattacharya, C. Chakraborty, and S. Bhattacharya, "Shunt compensation," in IEEE Industrial Electronics Magazine, vol. 3, no. 3, pp. 38-49, 2009.

[8] F. Z. Peng, "Application issues of active power filters," in IEEE Industry Applications Magazin, vol. 4, no. 5, pp. 21-30, 1998.

[9] S. Bhattacharya and D. Divan, "Design and implementation of a hybrid series active filter system," Proceedings of PESC '95-Power Electronics Specialist Conference, Atlanta, GA, USA, vol. 1, pp. 189-195, 1995.

[10] S. Bhattacharya, P.-T. Cheng and D. M. Divan, "Hybrid solutions for improving passive filter performance in high power applications," Proceedings of Applied Power Electronics Conference. APEC '96, San Jose, CA, USA, vol. 2, pp. 911-917, 1996.

[11] Bartosz Kędra, "Comparison of an active and hybrid power filter devices," 2014 16th International Conference on Harmonics and Quality of Power (ICHQP), Bucharest, pp. 556-560, 2014.

[12] Bhim Singh and Vishal Verma, "An indirect current control of hybrid active power filter for varying loads," in IEEE Transactions on Power Delivery, vol. 21, no. 1, pp. 178-184, 2006.

[13] H. Fujita and H. Akagi, "A practical approach to harmonic compensation in power systems-series connection of passive and active filter," in IEEE Transactions on Industry Applications, vol. 27, no. 6, pp. 1020-1025, 1991.

[14] V. Fabián Corasaniti, et al., "Hybrid active power filter for reactive and harmonics compensation in a distributed network," in IEEE Transactions on Industrial Electronics, vol. 56, no. 3, pp. 670-677, 2009.

[15] R. Inzunza and H. Akagi, "A 6.6-kV transformer less shunt hybrid active filter for installation on a power distribution system," in IEEE Transactions on Power Electronics, vol. 20, no. 4, pp. 893-900, 2005.

[16] H. Akagi, S. Srianthumrong, and Y. Tamai, "Comparison in circuit configuration and filtering performance between hybrid and pure shunt active filters," 8th IAS Annual Meeting on Conference Record of the Industry Applications Conference, 2003., Salt Lake City, UT, USA, vol. 2, pp. 1195-1202, 2003.

[17] C.-S. Lam, W.-H. Choi, M.-C. Wong, and Y.-D. Han, "Adaptive DC-link voltage-controlled hybrid active power filters for reactive power compensation," in IEEE Transactions on Power Electronics, vol. 27, no. 4, pp. 1758-1772, 2012.

[18] Bhattacharya, C. Chakraborty, and S. Bhattacharya, "Parallel connected shunt hybrid active power filters operating at different switching frequencies for improved performance," in IEEE Transactions on Industrial Electronics, vol. 59, no. 11, pp. 4007-4019, 2012.

[19] S. Rahmani, K. Hamadi, and A. Al-Haddad, "A Lyapunov-function-based control for a three-phase shunt hybrid active filter," in IEEE Transactions on Industrial Electronics, vol. 59, no. 3, pp. 1418-1429, 2012.

[20] S. Rahmani, A. Hamadi, K. Al-Haddad, and L. Dessaint, "A combination of shunt hybrid power filter and thyristorcontrolled reactor for power quality," in IEEE Transactions on Industrial Electronics, vol. 61, no. 5, pp. 2152-2164, 2014.

[21] C.-S. Lam et al., "Design and performance of an adaptive low-DC voltage-controlled LC-hybrid active power filter with a neutral inductor in three-phase four- wire power systems," in IEEE Transactions on Industrial Electronics, vol. 61, no. 6, pp. 2635-2647, 2014.

[22] Lin Chen, Yunxinang Xie and Zhi Zhang, "Comparison of Hybrid Active Power Filter Topologies and Principles," 2008 International Conference on Electrical Machines and Systems, Wuhan, pp. 2030-2035, 2008.

[23] Juha Turunen, Mika Salo and Heikki Tuusa, "Comparison of Series Hybrid Active Power Filters Based on Experimental Tests," 2005 European Conference on Power Electronics and Applications, Dresden, pp. 10 pp.-P.10, 2005.

[24] R. Balasubramanian, K. Parkavikathirvelu, R. Sankaran and Rengarajan Amirtharajan "Design, Simulation and Hardware Implementation of Shunt Hybrid Compensator Using Synchronous Rotating Reference Frame (SRRF)Based Control Technique," Electronics, vol. 8, no. 1, 2019.

[25] American National Standards Insitute, "IEEE Recommended Practices and Requirements for Harmonic Control in Electrical Power Systems," IEEE std. 519-1992, 1993.

[26] A. Dey, K. Mathew, K. Gopakumar, "A space-vector-based hysteresis current controller for a general n-level inverter-fed drive with nearly constant switching frequency control," in IEEE Transactions on Industrial Electronics, vol. 60, no. 5, pp. 1989-1998, 2013.

[27] H. Akagi, Y. Kanazawa, A. Nabae, "Instantaneous Reactive Power Compensators Comprising Switching Devices without Energy Storage Components," in IEEE Transactions on Industry Applications, vol. IA-20, no. 3, pp. 625-630, 1984.

[28] Samet Biricikab, Soydan Redifb, Özgür C. Özerdemc, Shafiuzzaman K. Khademd , Malabika Basu, "Real-Time Control of Shunt Active Power Filter under Distorted Grid Voltage and Unbalanced Load Condition using Self Tuning Filter," in IET Power Electronics, vol. 7, no. 7, pp. 1895-1905, 2014.

[29] J. Mindykowski, X. Xiaoyan, T. Tarasiuk, Y. Caijian, "An improved algorithm of compensating current generation for active power filters control," Measurement, vol. 63, pp. 187-194, 2015. 


\section{BIOGRAPHIES OF AUTHORS}

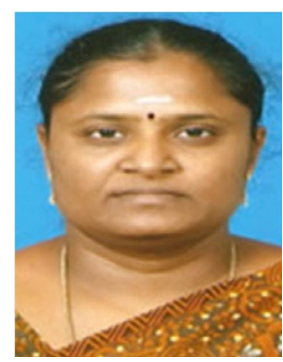

T. M. Thamizh Thentral, She received B.E. Electrical and Electronics Engineering from Bharathidasan University, Trichy in 1994 and M.E. Power Electronics and Drives from Anna University, 2008 respectively. She is currently pursuing Ph.D. in SRM Institute of Science and Technology, aalso working as an Assistant Professor in the Department of Electrical and Electronics Engineering SRM Institute of Science and Technology. Her area of interest are Power Electronics, Inverters, Converters and Power Quality.

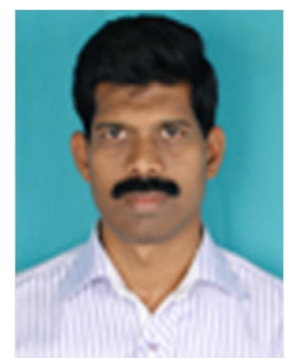

K. Vijayakumar has received B.E. degree in Electrical and Electronic Engineering from Annamalai University. M.Tech. (Power Systems) from Annamalai University and Ph.D. from SRM Institute of Science and Technology. He is currently working as Professor and Head in SRMIST. His area of research is Power electronic applications in Power system. His current research is focused on Optimizations, Hybrid energy systems and Deregulation.

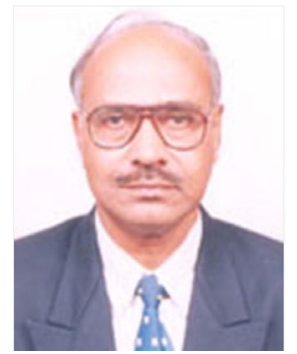

R. Jegatheesan completed his B.E. (Hons.) and M.Sc. (Engg) degree from Madras University. He completed his Ph.D. in IIT-Kanpur. He is currently working as Professor in EEE department at SRMIST, Chennai, India. His area of interests include Power System state estimation, Large Scale Power system, Optimization and Power system operation and control. 